\title{
Morbidity and mortality outcomes of COVID-19 patients with and without hypertension in Lagos, Nigeria: a retrospective cohort study
}

Akin Abayomi ${ }^{1}$, Akin Osibogun ${ }^{2,3^{*}}$ (D) Oluchi Kanma-Okafor ${ }^{2}$, Jide Idris ${ }^{1}$, Abimbola Bowale ${ }^{4}$, Ololade Wright ${ }^{5}$,

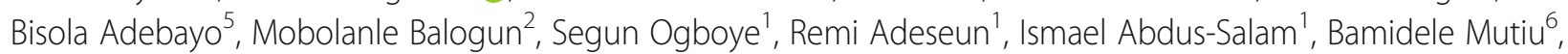
Babatunde Saka ${ }^{6}$, Dayo Lajide ${ }^{1}$, Sam Yenyi ${ }^{7}$, Rotimi Agbolagorite ${ }^{1}$, Oluwatosin Onasanya $^{3}$, Eniola Erinosho ${ }^{3}$, Joshua Obasanya ${ }^{8}$, Olu Adejumo ${ }^{4}$, Sunday Adesola ${ }^{4}$, Yewande Oshodi ${ }^{2}$, Iorhen E Akase ${ }^{9}$, Shina Ogunbiyi ${ }^{4}$, Adenike Omosun ${ }^{1}$, Femi Erinoso ${ }^{10}$, Hussein Abdur-Razzaq ${ }^{1}$, Nike Osa ${ }^{1}$ and Kingsley Akinroye ${ }^{11}$

\section{Abstract}

Background: The current pandemic of coronavirus disease (COVID-19) caused by the severe acute respiratory syndrome coronavirus 2 (SARS-CoV-2) has shown epidemiological and clinical characteristics that appear worsened in hypertensive patients. The morbidity and mortality of the disease among hypertensive patients in Africa have yet to be well described.

Methods: In this retrospective cohort study all confirmed COVID-19 adult patients ( $\geq 18$ years of age) in Lagos between February 27 to July 62,020 were included. Demographic, clinical and outcome data were extracted from electronic medical records of patients admitted at the COVID-19 isolation centers in Lagos. Outcomes included dying, being discharged after recovery or being evacuated/transferred.

Descriptive statistics considered proportions, means and medians. The Chi-square and Fisher's exact tests were used in determining associations between variables. Kaplan-Meier survival analysis and Cox regression were performed to quantify the risk of worse outcomes among hypertensives with COVID-19 and adjust for confounders. $P$-value $\leq 0.05$ was considered statistically significant.

\footnotetext{
* Correspondence: akinosibogun@yahoo.co.uk

${ }^{2}$ College of Medicine University of Lagos, Idi-Araba, Lagos, Nigeria

${ }^{3}$ Lagos State Primary Health Care Board, Lagos, Nigeria

Full list of author information is available at the end of the article
}

(c) The Author(s). 2021, corrected publication 2021. Open Access This article is licensed under a Creative Commons Attribution 4.0 International License, which permits use, sharing, adaptation, distribution and reproduction in any medium or format, as long as you give appropriate credit to the original author(s) and the source, provide a link to the Creative Commons licence, and indicate if changes were made. The images or other third party material in this article are included in the article's Creative Commons licence, unless indicated otherwise in a credit line to the material. If material is not included in the article's Creative Commons licence and your intended use is not permitted by statutory regulation or exceeds the permitted use, you will need to obtain permission directly from the copyright holder. To view a copy of this licence, visit http://creativecommons.org/ licenses/by/4.0/ 
Results: A total of 2075 adults with COVID-19 were included in this study. The prevalence of hypertension, the most common comorbidity, was $17.8 \%$ followed by diabetes (7.2\%) and asthma (2.0\%). Overall mortality was $4.2 \%$ while mortality among the hypertensives was $13.7 \%$. Severe symptoms and mortality were significantly higher among the hypertensives and survival rates were significantly lowered by the presence of additional comorbidity to $50 \%$ from $91 \%$ for those with hypertension alone and from $98 \%$ for all other patients $(P<0.001)$. After adjustment for confounders (age and sex), severe COVID-19and death were higher for hypertensives \{severe/critical illness: $\mathrm{HR}=2.41, P=0.001,95 \% \mathrm{Cl}=1.4-4.0$, death: $\mathrm{HR}=2.30, P=0.001,95 \% \mathrm{Cl}=1.2-4.6$, for those with hypertension only\} \{severe/critical illness: $\mathrm{HR}=3.76, P=0.001,95 \% \mathrm{Cl}=2.1-6.4$, death: crude $\mathrm{HR}=6.63, P=0.001,95 \% \mathrm{Cl}=3.4-1.6$, for those with additional comorbidities\}. Hypertension posed an increased risk of severe morbidity (approx. 4-fold) and death (approx. 7-fold) from COVID-19 in the presence of multiple comorbidities.

Conclusion: The potential morbidity and mortality risks of hypertension especially with other comorbidities in COVID-19 could help direct efforts towards prevention and prognostication. This provides the rationale for improving preventive caution for people with hypertension and other comorbidities and prioritizing them for future antiviral interventions.

Keywords: COVID-19, Nigeria, Hypertension, Comorbidities, Coronavirus, SARS-CoV-2 virus, Pandemic

\section{Introduction}

Globally, there is an ongoing pandemic of Coronavirus disease (COVID-19), an infectious disease caused by a newly discovered coronavirus called the Severe Acute Respiratory Syndrome Coronavirus 2 (SARS-CoV-2) [1]. The infection fatality rate (IFR) of this disease has been estimated at a range of around $0.5-1 \%[2,3]$, with higher rates among those aged 60 or older [4]. The majority of cases of COVID-19 experience mild to moderate respiratory illness and recover with supportive care. Serious illness is more likely with the elderly and those with underlying comorbidities like cardiovascular disease, chronic respiratory disease, diabetes, and cancer $[5,6]$.

Much earlier in a study in China, where the COVID-19 was first reported, it was found that $48 \%$ of patients had a comorbidity, with hypertension being the most prevalent (30\%), followed by diabetes (19\%) and coronary heart disease (8\%) [7]. In a study from Italy, it was reported that COVID19 deaths were mostly among people with comorbidities (99\%), the majority of these were hypertensive $(76.5 \%)[8,9]$. Studies have shown that hypertension imposes on those who suffer from it an increased risk of getting infected with COVID-19, experiencing worse symptomatology and complications and a 2-fold risk of dying from the infection. Hypertension was reported to have had a hazard ratio (HR) of 1.70 [95\% confidence interval (CI) $0.92-3.14$ ] to 3.05 (95\% CI 1.57-5.92) for mortality in some unadjusted epidemiological studies in China [7, 10].

High blood pressure is common among people over 60 years of age, the prevalence being nearly as high as two-thirds of this population. Long-term ill health and aging lead to a weakened immune system increasing the susceptibility of people with chronic illnesses to coronavirus infection. Along with the increased risk of infection and worsened outcomes among hypertensives, there is a growing concern that some medications used in the treatment may influence mortality in patients with COVID-19 [11, 12]. These medications such as angiotensin-converting enzyme (ACE) inhibitors and angiotensin receptor blockers (ARBs), cause a rise in blood levels of ACE2 [13]. The theory is that the COVID-19 virus infects human cells by forming a bond with ACE2, a requirement for viral entry into host cells [14], thus increasing individual susceptibility to infection and propagation of the virus [15]. Several other studies have however found no association between the use of these drugs and the severity of COVID-19 [16].

The epidemiological and clinical characteristics of patients with COVID-19 in terms of the detailed clinical course of illness, risk factors for mortality its spread and even its treatment are still being studied and documented. Understanding the potential effect of hypertension on the risk of mortality from COVID-19 could help clinicians to identify and characterize patients' prognoses at an early stage so as to provide timely intervention. This study, hence, was aimed at assessing the hypothesis that hypertension worsens the morbidity and mortality outcomes of confirmed COVID-19 patients.

\section{Methods}

\section{Study subjects and design}

This retrospective observational study was conducted using data collected from 2075 adult COVID-19 patients ( $\geq 18$ years of age) consecutively admitted across ten designated isolation and treatment centers and hospitals, with reverse transcription polymerase chain reaction (RT-PCR) test results confirming COVID-19. These 
patients received care at hospitals or isolation and treatment centers dedicated solely to the treatment of COVID-19, in Lagos, Nigeria from 27 February to 6 July 2020. This study was conducted to include only patients who had been admitted to care at the isolation centers as at the commencement of the study on 6 July 2020 . The strategy at that phase of the outbreak was containment, in the attempt to reduce community spread. Therefore, all identified positive cases were admitted to the isolation centers.

\section{Data collection}

Patients' data collected on admission included sociodemographic data, details of their medical history and comorbidities, symptoms, severity of symptoms on admission, clinical outcomes and status at the end of the study (recovery, transfer/evacuation or death). Data was collected at the hospital/isolation center using the electronic medical records created specifically for the Lagos State COVID-19 response. Data extracted for the purpose of this study was completely anonymized.

\section{Description of variables}

Sociodemographic data included the age, sex, health facility and epidemiological identifier. Details of their medical history were limited to the reported comorbidities. The patients' presenting symptoms were recorded and the severity of symptoms on admission was categorized as mild, moderate, severe, or critical. Asymptomatic patients were categorized as mild, while cases with cough, fever, respiratory rate $<30$ breaths per minute and peripheral capillary oxygen saturation $(\mathrm{spO} 2)>90 \%$ were categorized as moderate. Patients who had grunting respiration, respiratory rate $>30$ breaths per minute and $\mathrm{spO} 2<90 \%$ on admission were classified as severe. The patients categorized as critical cases were those in respiratory failure [17].

\section{History of hypertension}

The data on comorbidities including hypertension was based on the patient's report of the previous diagnosis prior to the infection with SARS-CoV-2. Those who required antihypertensive medication during hospitalization with no prior prescription were treated with antihypertensives, while those who had been on medications prior to admission, were treated with their usual prescribed medication. These patients were not stratified according to whether or not they were receiving antihypertensive while on admission.

\section{Outcomes}

The major outcomes after admission were discharged following recovery or death. Patients still receiving care as of July 6, 2020, who had neither been discharged, transferred nor had died were classified as 'yet undetermined'. Details of follow-up of patients after leaving the hospital or isolation center were not included in this dataset.

\section{Data management and analysis}

Data were analyzed using the SPSS version 20 and presented in frequencies and proportions. Descriptive statistics considered means \pm standard deviation (SD) for continuous variables that were normally distributed and median \pm interquartile range (IQR) for those identified as skewed. Bivariate analyses (Chi-square test (trend and non-trend) and the Fisher's exact test as required) were used in determining associations between variables. Kaplan-Meier survival analysis was done to compare mortality between hypertensives and patients without hypertension. The Cox proportional hazards model was used to quantify the risk of worse outcomes among hypertensives with COVID-19 and adjust for the effect of confounders. $p$-value $<0.05$ was considered statistically significant.

\section{Results}

The patients were predominantly less than 40 years of age and about a tenth of them were over 60 years of age. The median age of the patients was $40(\mathrm{IQR}=32-50)$ years, and the oldest was 98 years of age. The male to female ratio was $2: 1$. About a quarter $(23.3 \%)$ of the patients had at least one comorbidity including hypertension, other cardiovascular (CVS) diseases, diabetes, asthma, HIV, Hepatitis B, cancer, renal disease, sickle cell disease, tuberculosis and other lung diseases, while $17.8 \%$ had hypertension alone. Over $50 \%$ of them were asymptomatic or mildly symptomatic at the time of admission. Severity on admission ranged between mild to critical and over half of them (56.9\%) had mild symptoms; about $2 \%$ of them were in critical condition on admission and at the end of the study period, there was about $4 \%$ mortality (Table 1 ).

When the groups were stratified by the presence or absence of hypertension it was found that hypertensive cohorts were significantly older $(55.68 \pm 12.9$ vs $38.68 \pm$ $11.5)$ and there was an increasing proportion of hypertensives across the age groups ( $p$ for trend $=0.001$ ). Both cohorts were proportionately similar in sex distribution. A significant proportion of the hypertensive cohort suffered the worse forms of COVID-19; severe $(14.4 \%$ vs $3.2 \%)$ and critical (6.8\% vs $1.0 \%)$, compared to the nohypertension cohort ( $\mathrm{p}$ for trend $<0.001$ ). The time till the endpoint of admission irrespective of outcome was significantly different between both cohorts. The hypertensive group experienced a relatively shorter time on admission before the final outcome, with a median duration of admission shorter for hypertensives than for 
Table 1 Patient characteristics

\begin{tabular}{|c|c|c|}
\hline Variable & Frequency $(N=2075)$ & $\%$ \\
\hline \multicolumn{3}{|l|}{ Age (in years) } \\
\hline$<40$ & 1017 & 49.0 \\
\hline $40-49$ & 526 & 25.3 \\
\hline $50-59$ & 321 & 15.5 \\
\hline$>-60$ & 211 & 10.2 \\
\hline Median age (IQR), min-max & $40(32-50), 18-98$ & \\
\hline \multicolumn{3}{|l|}{ Sex } \\
\hline Male & 1379 & 66.5 \\
\hline Female & 696 & 33.5 \\
\hline \multicolumn{3}{|l|}{ Comorbidities $\left(n=2071^{\mathrm{a}}\right)$} \\
\hline Yes & 483 & 23.3 \\
\hline No & 1588 & 76.7 \\
\hline \multicolumn{3}{|l|}{ Type of comorbidity ${ }^{d}$} \\
\hline Hypertension & 369 & 17.8 \\
\hline Diabetes & 150 & 7.2 \\
\hline Asthma & 42 & 2.0 \\
\hline HIV/Hepatitis B & 15 & 0.7 \\
\hline Other CVS diseases & 14 & 0.6 \\
\hline Cancer & 15 & 0.7 \\
\hline Renal disease & 10 & 0.5 \\
\hline Sickle cell disease & 6 & 0.3 \\
\hline Tuberculosis \& other lung diseases & 7 & 0.3 \\
\hline \multicolumn{3}{|l|}{ Symptoms $\left(n=2071^{b}\right)$} \\
\hline Asymptomatic to mild & 1192 & 57.6 \\
\hline Symptomatic beyond mild & 879 & 42.4 \\
\hline \multicolumn{3}{|l|}{ Severity on admission $\left(n=2071^{\mathrm{C}}\right)$} \\
\hline Mild/asymptomatic & 1179 & 56.9 \\
\hline Moderate & 743 & 35.9 \\
\hline Severe & 107 & 5.2 \\
\hline Critical & 42 & 2.0 \\
\hline \multicolumn{3}{|l|}{ Discharge status } \\
\hline Determined & 1739 & 83.8 \\
\hline Yet undetermined (still on admission) & 336 & 16.2 \\
\hline \multicolumn{3}{|l|}{ Discharge status determined $(n=1739)$} \\
\hline Died & 73 & 4.2 \\
\hline Recovered & 1638 & 98.4 \\
\hline Transferred out/Evacuated & 28 & 1.6 \\
\hline
\end{tabular}

${ }^{\mathrm{a}}$ Missing $=4(0.2 \%){ }^{\mathrm{b}}$ Missing $=4(0.2 \%){ }^{\mathrm{c}}$ Missing $=4(0.2 \%)$

${ }^{\mathrm{d}}$ Multiple comorbidities reported by some patients

patients without hypertension (12(IQR $=8-14)$, $13(\mathrm{IQR}=10-14)$, respectively). The disease outcome was significantly different between the cohorts; $13.7 \%$ of those who were hypertensive died compared to $2.2 \%$ of patients without hypertension $(p=0.001)$ (Table 2).
There was a statistically significant difference in mortality and survival among hypertensive patients who had hypertension only and those hypertensives with multiple comorbidities. Similarly, the time till the endpoint was significantly different between those who died and those who survived. A higher proportion of hypertensives that had at least one other comorbidity died (27.5\%) compared to those who had hypertension alone $(8.1 \%)(P<$ 0.001 ). The proportion of hypertensives who died within the first 14 days $(21.0 \%)$ was higher compared to those whose deaths occurred beyond 2 weeks (2.0\%), implying that that death among hypertensives occurred mostly within the first 2 weeks of admission $(P<0.001)$. A greater proportion $(26.4 \%)$ of the hypertensives with other comorbidities died within the first weeks of admission compared to those who had hypertension only $(16.2 \%)(P=0.086)$, (Table 3).

The Kaplan-Meier estimates indicated that the COVID-19 survival rate for the patients without hypertension was 94, 91\% for patients with hypertension only and $50 \%$ for those with hypertension with other comorbidities. The log-rank test indicated that there was a statistically significant difference between the three survival rates $(p<0.001)$. The unadjusted hazard ratio (HR) indicated that in the risk of death there was a 4-fold increase among hypertensives and a 13-fold increase among hypertensives with additional comorbidities compared to those who were not hypertensive. Collectively, these results suggest that patients in the hypertensive group were less likely to survive (Fig. 1).

In both the unadjusted and adjusted multivariate analysis (adjusting for sex and age), Cox regression showed that the hypertensive groups had increased rates of severe COVID-19 and mortality. Prior to adjustment, severe/critical illness and death from COVID-19 were significantly associated with being hypertensive (severe/ critical illness: crude $\mathrm{HR}=4.21, p=0.001,95 \% \mathrm{CI}=2.7$ 6.5) (death: crude $\mathrm{HR}=3.70, p=0.001,95 \% \mathrm{CI}=2.0-6.7$ ) and having an additional comorbidity (severe/critical illness: crude $\mathrm{HR}=7.35, \quad p=0.001, \quad 95 \% \mathrm{CI}=4.5-11.8$ ) (death: crude $\mathrm{HR}=12.68, p=0.001,95 \% \mathrm{CI}=7.5-21.4$ ). After adjustment for confounders, the HR for severe illness and death were still higher than for patients without hypertension (severe/critical illness: $\mathrm{aHR}=2.41, p=$ $0.001,95 \% \mathrm{CI}=1.4-4.0$, death: $\mathrm{aHR}=2.30, \quad p=0.001$, $95 \% \mathrm{CI}=1.2-4.6$, for those with hypertension only) (severe/critical illness: aHR $=3.76, p=0.001,95 \% \mathrm{CI}=2.1-$ 6.4, death: $\mathrm{aHR}=6.63, p=0.001,95 \% \mathrm{CI}=3.4-1.6$, for those with additional comorbidities). The hypertensiononly patients were about 2 times as likely as patients without hypertension to develop severe disease and 2 times as likely as patients without hypertension to die while those with additional comorbidities were about 4 times as likely as those without hypertension to develop 
Table 2 Comparison of patients' characteristics and morbidity/ mortality against hypertensive status

\begin{tabular}{|c|c|c|c|c|c|}
\hline \multirow[t]{2}{*}{ Variable } & \multicolumn{3}{|c|}{ Hypertensive(n(\%)) } & \multirow[t]{2}{*}{$\mathrm{x}^{2}$} & \multirow{2}{*}{$\begin{array}{l}P \text { - } \\
\text { value }\end{array}$} \\
\hline & Yes & No & Total & & \\
\hline Age (in years) & & & & $457.47^{c}$ & 0.001 \\
\hline$<40$ & $33(8.9)$ & $983(57.8)$ & 1016 (49.1) & & \\
\hline $40-49$ & $96(26.0)$ & $429(25.2)$ & $525(\mathbf{2 5 . 4 ) )}$ & & \\
\hline $50-59$ & $118(32.0)$ & $203(11.9)$ & 321 (15.5) & & \\
\hline$>-60$ & $122(33.1)$ & $87(5.1)$ & 209 (10.1) & & \\
\hline Total & $369(100.0)$ & $1702(100.0)$ & $2071(100.0)$ & & \\
\hline Median age (IQR) & $55(47-63)$ & $37(30-45)$ & $40(32-50)$ & & \\
\hline Mean \pm SD & $55.62 \pm 12.9$ & $38.68 \pm 11.5$ & $41.72 \pm 13.4$ & $t=23.3$ & 0.001 \\
\hline Sex & & & & 0.47 & 0.492 \\
\hline Male & $251(68.0)$ & $1126(66.2)$ & $1377(64.5)$ & & \\
\hline Female & $118(32.0)$ & $576(33.8)$ & $694(33.5)$ & & \\
\hline Total & $369(100.0)$ & $1702(100.0)$ & $2071(100.0)$ & & \\
\hline Severity on admission & & & & $159.87^{c}$ & $<0.001$ \\
\hline Mild & $136(36.9)$ & $1043(61.3)$ & $1179(56.9)$ & & \\
\hline Moderate & $155(42.0)$ & $588(34.5)$ & 743 (35.9) & & \\
\hline Severe & $53(14.4)$ & $54(3.2)$ & $107(5.2)$ & & \\
\hline Critical & $25(6.8)$ & $17(1.0)$ & $42(2.0)$ & & \\
\hline Total & $369(100.0)$ & $1702(100.0)$ & $2071(100.0)$ & & \\
\hline Time till endpoint & & & & $5.24^{c}$ & 0.022 \\
\hline$<14$ days & $197(66.1)$ & $860(59.8)$ & $1057(60.9)$ & & \\
\hline $14-28$ & $100(33.6)$ & $557(38.7)$ & $657(37.8)$ & & \\
\hline$>28$ days & $1(0.3)$ & $22(1.5)$ & $23(1.3)$ & & \\
\hline Total & $298(100.0)$ & $1439(100.0)$ & $1737^{\mathrm{a}}(100.0)$ & & \\
\hline Median time (IQR) & $12(8-14)$ & $13(10-14)$ & & & \\
\hline Mean \pm SD & $11.06 \pm 5.47$ & $12.4 \pm 4.91$ & & & \\
\hline Discharge status determined & & & & 95.70 & $<0.001$ \\
\hline Died & $41(13.7)$ & $32(2.2)$ & $73(4.2)$ & & \\
\hline Recovered & $247(82.3)$ & $1391(96.7)$ & $1638(94.2)$ & & \\
\hline Transferred out/evacuated & $12(4.0)$ & $16(1.1)$ & $28(1.6)$ & & \\
\hline Total & $300(100.0)$ & $1439(100.0)$ & $1739^{b}(100.0)$ & & \\
\hline
\end{tabular}

${ }^{\mathrm{a}}$ Missing $=334(16.1 \%)^{\mathbf{b}}$

${ }^{\mathrm{C}} \mathrm{Chi}$-square test for trend

severe disease and about 7 times as likely to die of COVID-19 compared to those without hypertension (Table 4).

\section{Discussion}

The coronavirus disease (COVID-19) is relatively new and hence understudied. However, the available data has identified the importance of hypertension in the morbidity and mortality picture of the disease. The age and sex distribution found in this study are similar to the findings of a meta-analysis of the clinical characteristics and comorbidities among 1786 coronavirus patients with a median age of 41 years and a male to female ratio of 1.4:
1 [18]. The same study found a hypertension prevalence of $15.8 \%$, lower than was found in this study (17.8\%). Another study in Wuhan, China found almost a 2-fold higher prevalence [19]. However, in all three studies, the spectrum of comorbidities was the same and hypertension was the most common comorbidity.

Reports of increased incidence and severity of COVID-19 have stated that the severity is skewed towards the elderly population who have a higher prevalence of hypertension and are apparently at particular risk of being infected with the SARS-CoV-2 virus [20]. This study found that severity is related to hypertension and that the hypertensive group also experienced a 
Table 3 Mortality among COVID-19 hypertensive patients (with or without other comorbidities, $<$ or $>2$ week of admission)

\begin{tabular}{|c|c|c|c|c|c|}
\hline Variable & $\operatorname{Died}(n(\%))$ & Survived (Recovered) (n(\%)) & Total(n(\%)) & $x^{2}$ & $P$ \\
\hline Number of comorbidities & & & & 19.09 & $<0.001$ \\
\hline 1 (Hypertension only) & $16(8.1)$ & $181(91.9)$ & $197(100.0)$ & & \\
\hline$>2$ & $25(27.5)$ & $66(72.5)$ & $91(100.0)$ & & \\
\hline Total & $41(14.2)$ & $247(85.8)$ & $288(100.0)$ & & \\
\hline Time till endpoint & & & & & $<0.001^{*}$ \\
\hline$<14$ days & $39(21.0)$ & $147(79.0)$ & $186(100.0)$ & & \\
\hline$\geq 14-28$ & $2(2.0)$ & $100(98.0)$ & $101(100.0)$ & & \\
\hline Total & $41(14.2)$ & $247(85.8)$ & $288(100.0)$ & & \\
\hline \multicolumn{6}{|l|}{ Endpoint within 2 weeks $(n=186)$} \\
\hline Hypertension only & $16(16.2)$ & $83(83.8)$ & $99(100.0)$ & 2.95 & 0.086 \\
\hline Hypertension with other comorbidities & $23(26.4)$ & $64(73.6)$ & $87(100.0)$ & & \\
\hline Total & $39(21.0)$ & $147(79.0)$ & $186(100.0)$ & & \\
\hline
\end{tabular}

*Fishers exact $p$

significantly shorter time on admission before the final outcome. This could be explained by the significantly higher proportion of worse disease outcomes (death) among the hypertensives. While there is an overrepresentation of hypertension among hospitalized and critically ill COVID-19 patients, expert reports have expressed uncertainty whether hypertension is more causal or if other confounders such as age and other comorbidities associated with hypertension augment its role [21]. In the current study, adjustment for confounders meant that patients with hypertension were at a greater risk of increased severity and death from COVID-19 as was seen in a much smaller study in Wuhan, China [22]. Meanwhile, even though it was found in another study that there was a significant two-fold higher risk of mortality due to hypertension when compared with patients with no hypertension [16], the current study found in addition, a significant difference in the potential of dying or surviving among hypertensives to be augmented in the presence of at least one additional comorbidity.

To corroborate the finding of this study that hypertension posed a greater risk of death among COVID-19 patients, a study in China reported that chronic hypertension was more frequent among COVID-19 patients who died compared with those who recovered [23]. Also similar to the finding that hypertension had an HR of 3.70 (crude) for death in 369 patients admitted

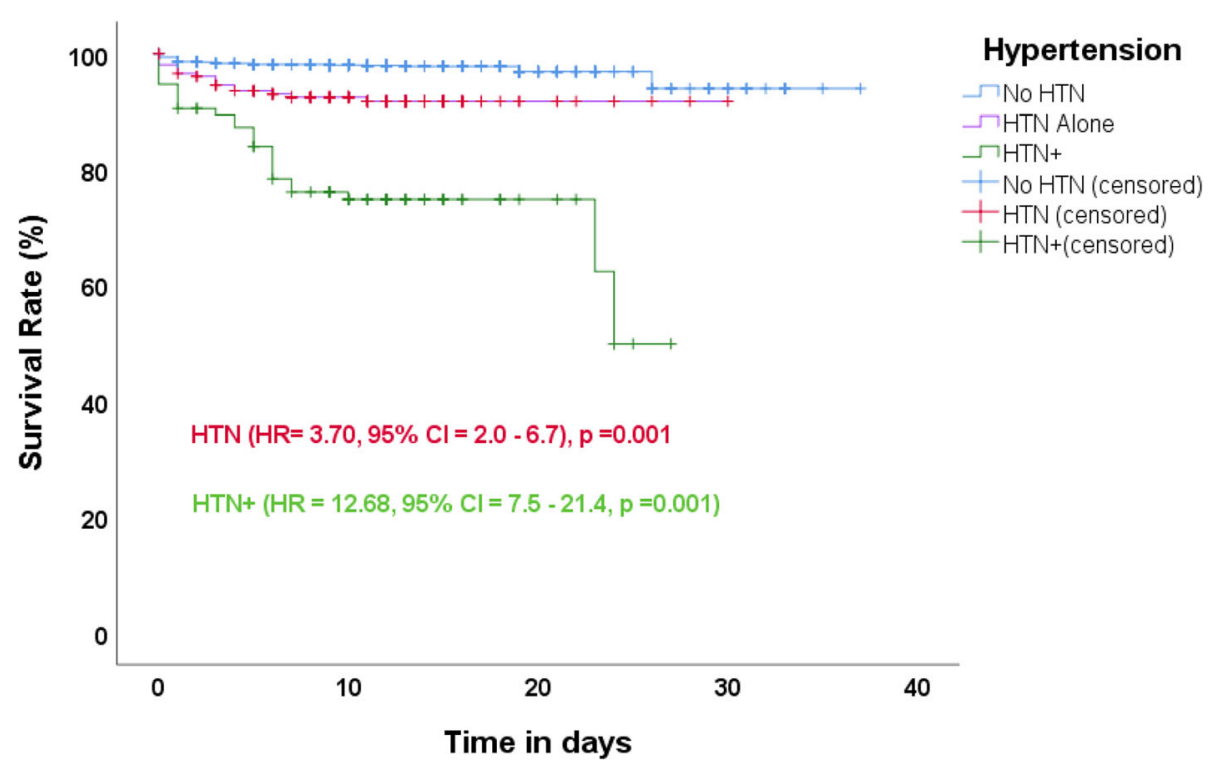

Fig. 1 Kaplan-Meier survival curves for mortality among COVID-19 patients with and without hypertension or with additional comorbidities 
Table 4 Cox regression for risk of increased severity and death among patients with hypertension compared with patients without hypertension. (adjusting for sex and age)

\begin{tabular}{|c|c|c|c|c|c|c|}
\hline \multirow[t]{2}{*}{ Variable } & \multirow[b]{2}{*}{ HR } & \multicolumn{3}{|c|}{ Unadjusted } & \multicolumn{2}{|c|}{ Adjusted } \\
\hline & & $95 \% \mathrm{Cl}$ & $p$-value & aHR & $95 \% \mathrm{Cl}$ & $p$-value \\
\hline \multicolumn{7}{|c|}{ Severity (Severe/critical) } \\
\hline HTN & 4.21 & $2.7-6.5$ & 0.001 & 2.41 & $1.4-4.0$ & 0.001 \\
\hline $\mathrm{HTN}+$ & 7.35 & $4.5-11.8$ & 0.001 & 3.76 & $2.1-6.4$ & 0.001 \\
\hline \multicolumn{7}{|c|}{ Outcome (death) } \\
\hline HTN & 3.70 & $2.0-6.7$ & 0.001 & 2.30 & $1.2-4.6$ & 0.019 \\
\hline $\mathrm{HTN}+$ & 12.68 & $7.5-21.4$ & 0.001 & 6.63 & $3.4-12.6$ & 0.001 \\
\hline
\end{tabular}

HTN hypertension, HTN+ hypertension plus other comorbidities, HR Hazard ratio, aHR Adjusted hazard ratio

for COVID-19 another study found an HR of 3.05 in 191 hypertensive patients with COVID-19 [19]. Another study, however, found that hypertension has a lower HR of 1.70 for death in 201 patients with COVID-19 [12]. The implications of the findings of this study are that hypertension is disproportionately more frequently found among COVID-19 patients than other comorbidities and that severe COVID-19 disease and a relatively shorter time to death are associated with being hypertensive, especially in patients who have other comorbidities.

This study was limited because data on hypertensive medication were not included in the dataset. It would have been useful to consider this because there is currently limited clinical evidence of the influence of antihypertensive medication on the prognosis of COVID-19. Nevertheless, continuing a patient's usual antihypertensive treatment is recommended [24]. Also, the patients in this study were only studied till the end of their stay in the COVID-19 isolation ward. It would have been interesting and beneficial to study the patient beyond the time of discharge.

\section{Conclusion}

The role of other comorbidities worsening the severity and outcomes of COVID-19 has been highlighted in this study. This recognition of the potential morbidity and mortality risks of hypertension especially with other comorbidities in COVID-19 could help direct efforts towards prevention and prognostication. This provides the rationale for improving preventive caution for people with hypertension and other comorbidities and prioritizing them for future antiviral interventions. Studies that demonstrate causation would be beneficial as understanding about COVID-19 improvements. Until more information is available to guide the treatment and management of COVID-19 patients with hypertension, it is important to control blood pressure according to current clinical practice guidelines.

\section{Abbreviations}

ACE: Angiotensin-converting enzyme; ARBs: Angiotensin receptor blockers; HTN: Hypertension; HTN + : Hypertension with other comorbidities;

HR: Hazard ratio; aHR: Adjusted hazard ratio

\section{Supplementary Information}

The online version contains supplementary material available at https://doi. org/10.1186/s41256-021-00210-6.

Additional file 1: Table S1. Cox regression for risk of death among patients with hypertension compared with patients without hypertension. (adjusting for Age, sex, diabetes mellitus, renal diseases, HIV/HBV co-infection, asthma, other cardiovascular diseases and cancer). Table S2. Distribution of comorbidities in patients with and without hypertension.

\section{Acknowledgements}

The authors wish to place on record the full support of the Incident Commander for the response to the COVID-19 outbreak in Lagos State, Mr. Babajide Sanwo-Olu, Governor of Lagos State and the Deputy Governor Dr. Kadiri Hamza by making available resources to conduct researches as part of the counter-measures to the outbreak. Several health workers in the frontline were responsible for caring for the patients and keeping the records.

\section{Authors' contributions}

$A A, A O, J$, and RA, contributed to the conceptualization and design of the study. AB, BA, IA, BM, BS, SY, RA, OO, EE, JO, OA, SA, YO, IA, SO, contributed to data generation and quality as well as manuscript review. OKO, OW, $\mathrm{FE}$, contributed to data cleaning, analysis and interpretation. $\mathrm{AO}, \mathrm{OKO}, \mathrm{Jl}$, and $\mathrm{RA}$, contributed to manuscript development. SO, AOO, OKO, DL, HAR, NO, $K A$, contributed to the manuscript review. All authors read and approved the final manuscript.

\section{Funding}

Funding for this study was by the Government of Lagos State through its COVID-19 Outbreak Response and Countermeasure. However, the Government played no role in the design of the study, and collection, analysis, and interpretation of data and in writing the manuscript.

\section{Availability of data and materials}

The datasets generated and/or analyzed during the current study are not publicly available because of ethical restrictions but are available from the corresponding author on reasonable request.

\section{Declarations}

Ethics approval and consent to participate

Ethical approval was obtained from The Lagos State University Teaching Hospital Health Research Ethics Committee. Ethical review provided a waiver of written informed consent for this study.

\section{Consent for publication}

Not applicable.

\section{Competing interests}

The authors declare that they have no competing interests.

\section{Author details}

${ }^{1}$ Lagos State Ministry of Health/Lagos Incident Management Command System, Lagos, Nigeria. ${ }^{2}$ College of Medicine University of Lagos, Idi-Araba, Lagos, Nigeria. ${ }^{3}$ Lagos State Primary Health Care Board, Lagos, Nigeria. ${ }^{4}$ Mainland Hospital, Yaba, Lagos, Nigeria. ${ }^{5}$ Lagos State University College of Medicine, Lagos, Nigeria. 'Lagos State Biobank, Lagos, Nigeria. ${ }^{7}$ World Health Organization, Nigeria Office, Abuja, Nigeria. ${ }^{8}$ Nigeria Centre for Disease Control, Abuja, Nigeria. ${ }^{~} L a g o s$ University Teaching Hospital, Lagos, Nigeria. ${ }^{10}$ Lagos State University Teaching Hospital, Lagos, Nigeria. ${ }^{11}$ Nigerian Heart Foundation, Lagos, Nigeria. 
Received: 30 August 2020 Accepted: 20 June 2021

Published online: 29 July 2021

\section{References}

1. Wu Z, McGoogan JM. Characteristics of and important lessons from the coronavirus disease 2019 (COVID-19) outbreak in China: summary of a report of 72314 cases from the Chinese Center for Disease Control and Prevention. JAMA. 2020;323(13):1239-42.

2. Mallapaty S. How deadly is the coronavirus? Scientists are close to an answer. Nature. 2020;582:467-8.

3. Russell TW, Hellewell J, Jarvis Cl, van Zandvoort K, Abbott S, Ratnayake R, et al. Estimating the infection and case fatality ratio for coronavirus disease (COVID-19) using age-adjusted data from the outbreak on the Diamond Princess cruise ship, February 2020. Euro Surveill. 2020;25(12):2000256.

4. Verity R, Okell LC, Dorigatti I, Winskill P, Whittaker C, Imai N, et al. Estimates of the severity of coronavirus disease 2019: a model-based analysis. Lancet Infect Dis. 2020;20(6):669-77.

5. World Health Organization. Coronavirus. Available at: https://www.who.int/ health-topics/coronavirus\#tab=tab_1. Accessed 6 Aug 2020.

6. Fang L, Karakiulakis $\mathrm{G}$, Roth M. Are patients with hypertension and diabetes mellitus at increased risk for COVID-19 infection? [published correction appears in Lancet Respir Med. 2020 Jun;8(6):e54]. Lancet Respir Med. 2020; 8(4):e21. https://doi.org/10.1016/S2213-2600(20)30116-8.

7. Zhou F, Yu T, Ronghui D, Fan G, Liu Y, Liu Z, et al. Clinical course and risk factors for mortality of adult inpatients with COVID-19 in Wuhan, China: a retrospective cohort study. Lancet. 2020;395(10229):1054-62. https://doi. org/10.1016/S0140-6736(20)30566-3

8. Istituto Superiore di Sanità. Report sulle caratteristiche dei pazienti deceduti positivi a COVID-19 in Italia II presente report è basato sui dati aggiornati al 13 Marzo 2020. https://www.epicentro.iss.it/coronavirus/bollettino/ReportCOVID-2019_17_marzo-v2.pdf. Accessed 6 Aug 2020.

9. Doorn-Khosrovani SBW, Roy AP. Rapid Response: COVID-19: learning from the claim data of those who were severely affected but also from their asymptomatic household members. Available at: https://www.bmj.com/ content/368/bmj.m1086/rr-1. Accessed 6 Aug 2020.

10. Wu C, Chen X, Cai Y, Xia J, Zhou X, Xu S, et al. Risk factors associated with acute respiratory distress syndrome and death in patients with coronavirus disease 2019 pneumonia in Wuhan, China. JAMA Intern Med. 2020. https:// doi.org/10.1001/jamainternmed.2020.0994

11. Vaduganathan M, Vardeny O, Michel T, McMurray JJV, Pfeffer MA, Solomon SD. Renin-angiotensin-aldosterone system inhibitors in patients with Covid-19. N Engl J Med. 2020;382(17):1653-9. https://doi.org/10.1056/ NEJMsr2005760.

12. Patel $A B$, Verma A. COVID-19 and angiotensin-converting enzyme inhibitors and angiotensin receptor blockers: what is the evidence? JAMA. 2020; 323(18):1769-70. https://doi.org/10.1001/jama.2020.4812.

13. Vuille-dit-Bille RN, Camargo SM, Emmenegger L, Sasse T, Kummer E, Jando J, et al. Human intestine luminal ACE2 and amino acid transporter expression increased by ACE-inhibitors. Amino Acids. 2015;47(4):693-705. https://doi. org/10.1007/s00726-014-1889-6.

14. Hoffmann M, Kleine-Weber H, Schroeder S, Krü ger N, Herrler T, Erichsen S, et al. SARS-CoV-2 cell entry depends on ACE2 and TMPRSS2 and is blocked by a clinically proven protease inhibitor. Cell. 2020;181(2):271-80. https://doi. org/10.1016/j.cell.2020.02.052

15. Wrapp D, Wang N, Corbett KS, Goldsmith JA, Hsieh CL, Abiona O, et al. Cryo-EM structure of the 2019-nCoV spike in the prefusion conformation. Science. 2020;367(6483):1260-3. https://doi.org/10.1126/science.abb2507.

16. Gao C, Cai Y, Zhang K, Zhou L, Zhang Y, Zhang X, et al. Association of hypertension and antihypertensive treatment with COVID-19 mortality: a retrospective observational study. Eur Heart J. 2020;41(22):2058-66. https:// doi.org/10.1093/eurheartj/ehaa433.

17. Bowale A, Abayomi A, Idris J, Omilabu S, Abdus-Salam I, Adebayo B, et al. Clinical presentation, case management and outcomes for the first 32 COVID-19 patients in Nigeria. Pan Afr Med J. 2020;35(2):24. https://doi.org/1 0.11604/pamj.supp.2020.35.2.23262

18. Paudel SS. A meta-analysis of 2019 novel coronavirus patient clinical characteristics and comorbidities. Res Square. 2020. https://doi.org/10.212 03/rs.3.rs-21831/v1 Accessed 18 Apr 2020, https://www.researchsquare. com/article/rs-21831/v1.
19. Zhou F, Yu T, Du R, et al. Clinical course and risk factors for mortality of adult inpatients with COVID-19 in Wuhan, China: a retrospective cohort study. Lancet. 2020;395(10229):1054-62.

20. Schiffrin EL, Flack JM, Ito S, Muntner P, Webb RC. Hypertension and COVID19. Am J Hypertens. 2020;33(5):373-4. https://doi.org/10.1093/ajh/hpaa057.

21. Arjun Kanwal A, Agarwala A, Martin LW, Handberg EM, Yang E. COVID-19 and hypertension: what we know and don't know. Am Coll Cardiol Expert Anal. https://www.acc.org/latest-in-cardiology/articles/2020/07/06/08/15/ covid-19-and-hypertension. Accessed 7 Aug 2020.

22. Shi S, Qin M, Shen B, Cai Y, Liu T, Yang F, et al. Association of cardiac injury with mortality in hospitalized patients with COVID-19 in Wuhan, China. JAMA Cardiol. 2020. https://doi.org/10.1001/jamacardio.2020.0950

23. Chen T, Wu D, Chen H, Yan W, Yang D, Chen G, et al. Clinical characteristics of 113 deceased patients with coronavirus disease 2019: retrospective study. BMJ 2020;368:m1091. Impact of antihypertensive treatments in COVID-19 2065. Downloaded from https://academic.oup.com/eurheartj/article-abstra ct/41/22/2058/5851436 on 29 July 2020.

24. European Society of Cardiology. Position Statement of the European Society of Cardiology (ESC) Council on Hypertension on ACE Inhibitors and Angiotensin Receptor Blockers. https://www.escardio.org/Councils/Councilon-Hypertension-(CHT)/News/position-statement-of-the-esc-councilonhypertension-on-ace-inhibitors-and-ang. Accessed 7 Aug 2020.
Ready to submit your research? Choose BMC and benefit from:

- fast, convenient online submission

- thorough peer review by experienced researchers in your field

- rapid publication on acceptance

- support for research data, including large and complex data types

- gold Open Access which fosters wider collaboration and increased citations

- maximum visibility for your research: over $100 \mathrm{M}$ website views per year

At BMC, research is always in progress.

Learn more biomedcentral.com/submissions 